\title{
ANALYSIS OF L-SHAPE BUILDING WITH LIFT CORE AT DIFFERENT LOCATIONS AND ITS TORSIONAL EFFECT
}

\author{
Sushil Adhikari ${ }^{1, *}$, Tek Bahadur Katuwal ${ }^{1}$, Dipak Thapa ${ }^{1}$, Suraj Lamichhane ${ }^{2}$, and Dhurba \\ Adhikari $^{1}$ \\ ${ }^{1}$ Department of Civil and Geomatics Engineering, Pashchimanchal Campus, IOE, TU, Nepal \\ ${ }^{2}$ Department of Civil Engineering, Pulchowk Campus, IOE, TU, Nepal \\ *E-mail: sushiladhikari40@gmail.com
}

\begin{abstract}
In L-shape building, lift core wall is an important element for strengthening the structure of high seismic zone area. Seismic zone V is considered for most of the buildings in Nepal, which will cause maximum base shear to the structure. This study focuses the use of lift core in five and ten-storey building to resist the seismic forces, and the effect of the lift core is also taken into consideration. Based on the location of the lift core, these building are further subdivided into different models; Lift at outer corner (model 1), lift at lower edge corner (model 2), lift at upper edge corner (model 3), lift at lower and upper edge corner (model 4), lift at inner corner (model 5), and lift at inner and outer corner (model 6). Equivalent static method and response spectrum analysis was used for the analysis. The structural responses were measured in terms of modal periods, displacement, drift ratio, and torsional irregularities. Results from this study indicate that building with lift core wall at inner and outer (model 6) and lift at lower and upper edge corner (model 4) shows the minimum drift ratio, torsional irregularities, displacement and natural time period which lies within permissible limit of torsional irregularities. Hence, it can be concluded that the location of the lift core affects the torsion of an L-shape plan asymmetric building. Designing two lift core at the inner and outer corner (model 6) and lower and upper edge corner (model 4) is found to be effective in reducing the torsion.
\end{abstract}

\section{Keywords}

L-shape, torsional irregularities, displacement, drift ratio, lift core

\section{Introduction}

In structural engineering, earthquake engineering is the most important part in research field. Peoples are facing many problems due to earthquake disaster and these impacts are inevitable. However, effects of earthquake can be minimized by improving the strength and stability of structure during design and construction period. During an earthquake event, many factors influences the stability of the building structure including magnitude of earthquake force, soft storey, setback and irregularities (Setia and Sharma, 2012); (Sarkar, et al., 2010). Particularly, plan irregular building is most sensitive to torsional response due to the unbalanced distribution of mass, stiffness 
and strength (Rajalakshmi, et al., 2015).

Nepal is located in high seismically vulnerable zone. Two tectonic plates, Indian plate and Eurasian plate meets the Himalayas along a fault line. The location for the perfectly regular building rarely occurs in Nepal. However, with the advancement in engineering sector, nowadays, many asymmetric building structures in plan or in elevations with lift core are designed and constructed. Structural irregularities are very difficult to define in their principle and nature. Therefore, the plan configuration selection of building plays a vital role in earthquake resisting structure. During the seismic action, irregular buildings are more vulnerable and easily damaged compared to the regular building (Abdel Raheem, et al., 2018; Haque, 2016). Asymmetric building consisting of lift core are more resistant to damage by seismic action. Particularly, the perfect location of the lift core during planning and designing stage play a crucial role in improving and strengthening of seismic capacity of these building. Proper and in-depth analysis should be done in structural irregularities in order to avoid an unexpected change in mass and rigidity of the building structure( Vahadane and Sir, 2016). The main objective of this study is to analyze the torsional irregularities of L-shape building with lift core at different locations.

\section{Literature review}

A building is said to be torsionally irregular, when the maximum horizontal displacement of any floor in the direction of the lateral force at one end of the floor, is more than 1.5 times its minimum horizontal displacement at the far end of the same floor in that direction. When the value of $\Delta \max / \Delta \min$ will be greater than 1.5 , then it indicates the torsional irregularity of building structures (IS 1893, 2016). Powale and Pathak study the $\mathrm{S}$ and L shaped building structure and compared their twisting/ torsional effect. They analyzed the building using time history analysis of a 33 Storey R. C. and studied the torsional effect for irregular plan. It was found that the $\Delta \max / \Delta \min$ ratio for ' $\mathrm{L}$ 'shaped building in $\mathrm{X}$ direction is more than 1.5 and hence the building is torsionally irregular. However, $\Delta \max / \Delta \min$ ratio for 'S'shaped building in both direction is less than 1.5 which shows that the building is regular. Thus, it can be concluded that ' $L$ ' shaped plan buildings show inferior earthquake resistance than ' $S$ ' shaped plan buildings and torsional irregularity is the primary point of consideration (Powale and Pathak, 2019). Increase in peak displacement demand of a low-rise asymmetric building that incorporates C-shaped cores was investigated and time history analysis was used to analyse displacements response of a single degree of freedom structure, which is in torsionally, coupled vibration modes. The displacement demands of the building was verified using a dynamic time-history analysis in a finite element-modelling program. It can be concluded that placing a single lift core at the perimeter of a building created plan asymmetry in plan and subsequently, produce large torsional response (Hoult et. al, 2015). T-shaped reinforced concrete building was investigated and the sensitivity of lift core positions was studied by comparing the percentage difference of the maximum torsional moment and building deformation. Analysis was done by generating 6-storey and 12-storey building models with SAP2000 software. The results demonstrated that the magnitude of the torsional moment at column of T- Shape plan asymmetric building was significantly influenced by lift core location 
and particularly true for all building heights. Thus, it suggest that the torsional effct can be minimized by designing two lift cores at the far end of the top wing (Abdullah et. al, 2017). Similarly, in another study, the effect of plan configuration irregularity when subjected to the varying angle of the input response spectrum was evaluated. One regular and six different L-shaped RC building frames were considered for modelling and for numerical analysis. Equivalent static lateral force method and response spectrum analysis (dynamic analysis) was used for analysis. Furthermore, story displacement, inter-story drift ratio, torsional irregularity ratio, torsional diaphragm rotation, normalized base shear force, and overturning moment were measured in terms of structural responses. It was observed that plan irregularity configuration building are more sensitive than symmetrical building model and seismic response demand was significantly increased in the finite element models when subjected to a 135-degree angle as compared to the zero degree angle model. The study also revealed that the torsional moment increases with the increase in the plan irregularity (Khanal and Chaulagain, 2020).

\section{Methodology}

\subsection{Building data}

L-shape building models with five storey and ten storey, each storey having $3 \mathrm{~m}$, were used in this study. To study the torsional effect of each five storey and ten storey building, six different lift core positions were selected. The shear wall section of the lift core was $2 \mathrm{~m} \times 2 \mathrm{~m}$. The plan view and the proposed lift core positions of the L- shape building are shown in Figure 1. The detail of the building models are shown in Table 1.
Table 1 : Detail of the building models

\begin{tabular}{|l|l|l|}
\hline \multirow{2}{*}{$\begin{array}{l}\text { Height of } \\
\text { building }\end{array}$} & 5-storey & $15 \mathrm{~m}$ \\
\cline { 2 - 3 } & 10-storey & $30 \mathrm{~m}$ \\
\hline Concrete grade & M20 \\
\hline Steel grade & Fe500 \\
\hline
\end{tabular}

In this study, six building models of five storey and six building models of ten storey with different locations of lift core wall were considered. Building models were designed according to IS 456, 2000. The sizes of column and beam were $450 \mathrm{~mm} \times 450 \mathrm{~mm}$ and $250 \mathrm{~mm}$ $\times 500 \mathrm{~mm}$, respectively. The thickness of the slab, exterior wall, interior wall and lift core wall were $150 \mathrm{~mm}, 230 \mathrm{~mm}, 125 \mathrm{~mm}$ and $200 \mathrm{~mm}$, respectively. The Response spectrum analysis was carried out by considering horizontal loads and self-weight of the members according to (IS 875 : 1987) (part 2) and (IS 875 : 1987) (part 1) respectively, live load on floors and waist slab were $3 \mathrm{kN} / \mathrm{m}^{2}$ and $4 \mathrm{kN} / \mathrm{m}^{2}$ respectively. Floor finish $1.5 \mathrm{kN} / \mathrm{m}^{2}$, exterior wall load 11.04 $\mathrm{kN} / \mathrm{m}$, and interior wall load $6 \mathrm{kN} / \mathrm{m}$ was considered in this study. The seismic details were considered as per IS 1893, 2002. Seismic parameters of the structure are presented in Table 2.

Table 2: Seismic parameters

\begin{tabular}{|l|l|}
\hline Earthquake zone & $\mathrm{V}$ \\
\hline Zone Factor $(\mathrm{Z})$ & 0.36 \\
\hline Importance factor $(\mathrm{I})$ & 1.5 \\
\hline Soil type & Type II \\
\hline Damping ratio & $5 \%$ \\
\hline Reduction factor $(\mathrm{R})$ & 5 \\
\hline
\end{tabular}


$a$

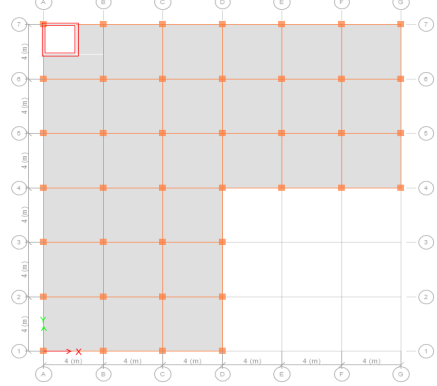

$c$

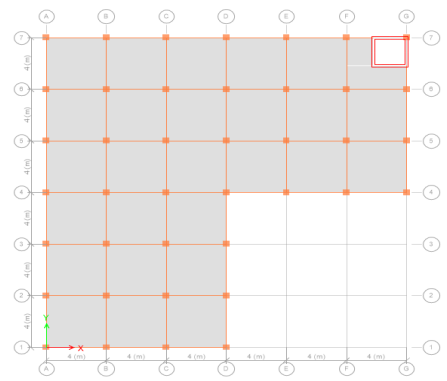

$e$

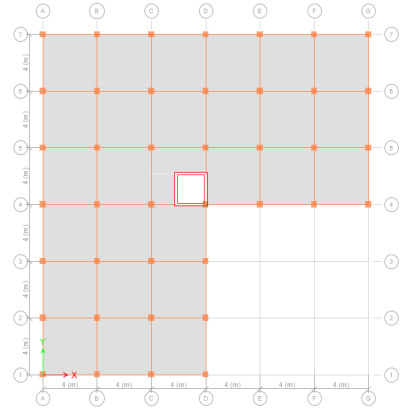

$g$

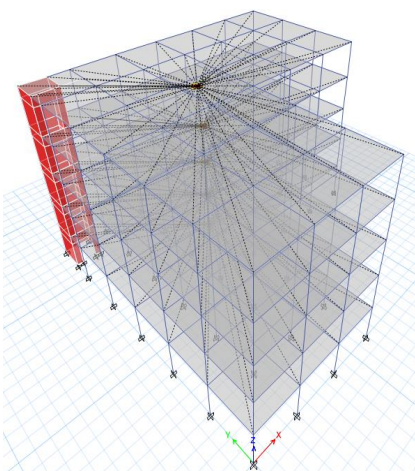

$b$

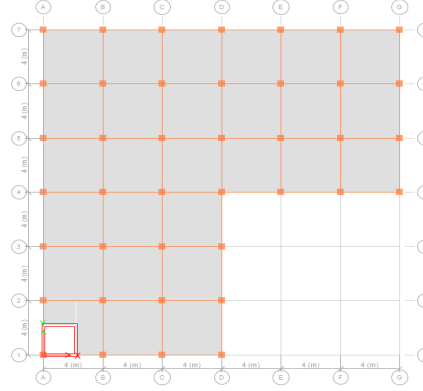

$d$

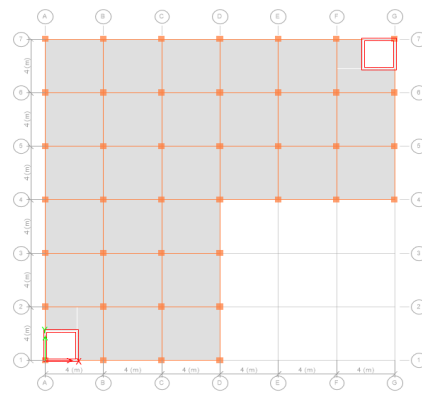

$f$

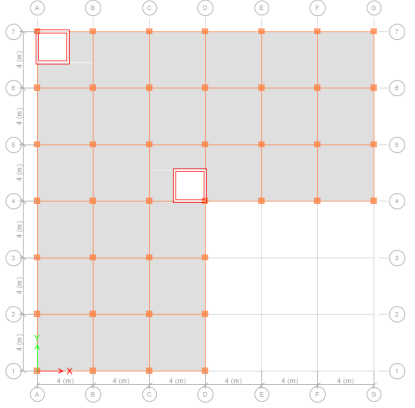

$h$

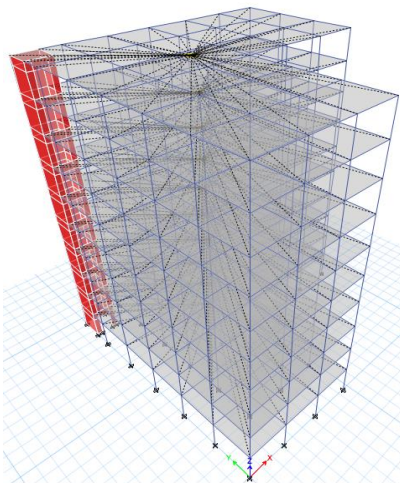

Figure 1: Finite element models under study (a) Lift at outer corner (Model 1), (b) Lift at lower edge corner (Model 2), (c) Lift at upper edge corner (Model 3), (d) Lift at lower and upper edge corner (Model 4), (e) Lift at inner corner (Model 5), (f) Lift at inner and outer corner (Model 6), (g) 3D model of five storey, and (h) 3D model of ten storey 


\section{$4 \quad$ Result and Discussions}

The linear static and response spectrum analysis for the models were carried out using ETABS 2018 ultimate v18.1.1. The seismic details were incorporated in accordance to the IS code 1893:2002. The torsional irregularity was found in reference to IS 1893, 2016. Therefore, the analysis was carried out in order to find the most torsional irregular structure based on different torsion parameters.

\subsection{Model period}

The twelve mode numbers versus the natural period of vibration are shown in Figure 2.

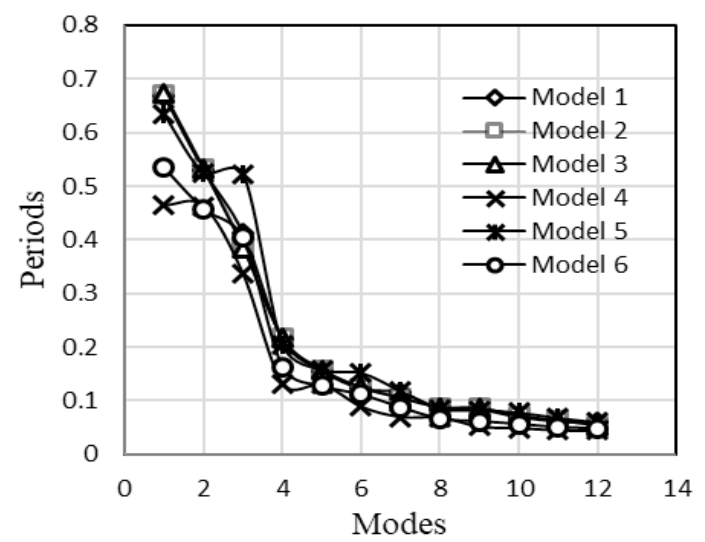

(a)

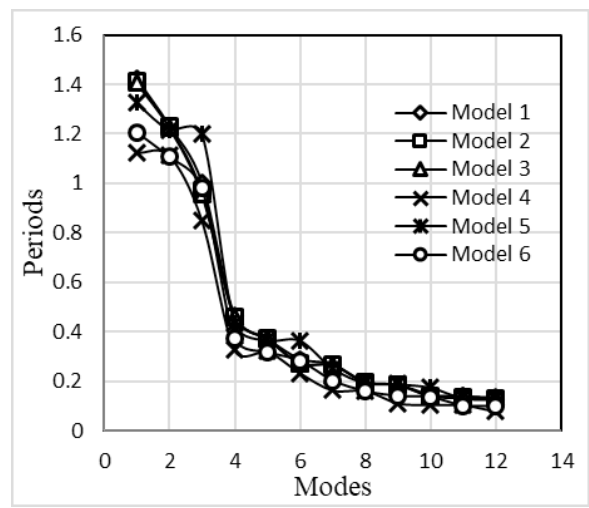

(b)

Figure 2: Model periods (a) Model period of 5 storey (b) Model period of 10 storey

According to figure 2 (a), model 3 showed the maximum natural period of 0.6733 seconds and the model 4 showed the minimum value of 0.465 seconds. Similarly, in figure 2 (b), model 1 showed the maximum natural period of 1.423 seconds and the model 4 showed the minimum value of 1.124 seconds. In both the cases, it is suggested that the structure with higher period of vibration have low resistance to seismic actions. Building having lift core at inner corner (model 5), inner-outer corner (model 6), and upper and lower edge corner (model 4) shows lowest period of vibration because it is rigid as compared to other remaining structure in both five storey and ten storey building. Specially, model 4 of five- storey demonstrate less flexibility and high resistance to seismic actions and model 3 of five- storey and model 1 of ten-storey demonstrate more flexibility and low resistance to seismic actions. Thus, more flexible and longer period design shows lesser accelerations than a stiffer building.

\subsection{Torsional irregularity}

Table 3 shows the torsional irregularities of the six-model building of five storey and ten storey. The torsional irregularities of model 1 to 6 of five storey and ten storey are shown in table 3. In case of 5-storey, building having lift core at outer corner (model 1), lower edge corner (model 2) and upper edge corner (model 3) has $\Delta \max / \Delta \min >1.5$ and lies outside the range of permissible limit. However, other remaining model building has $\Delta \max / \Delta \min <1.5$ and lies within permissible limit. Similarly, in case of ten storey building, all type of lift core positions lies within the permissible limit. After placing two-lift core in model 4 , it is observed that torsional irregularity ratio $(\Delta \max / \Delta \min )$ decrease because of the increment in lift core number, which are capable of holding the 
Nepal Engineers' Association, Gandaki

structure against twisting or torsion. However, in case of single lift-core present in a building, lift core at inner corner (model 5) illustrate the minimum torsional value because in this position lift core is present in the highly stressed zone of the building. Also, these results comply with the code suggested ratio 1.5 (IS 1893, 2016).

Table 3: Torsional irregularities

\begin{tabular}{|l|l|l|l|l|l|l|l|}
\hline \multirow{2}{*}{ Model } & \multicolumn{3}{|c|}{ X-direction } & \multicolumn{3}{c|}{ Y-direction } & Permissible \\
\cline { 2 - 9 } & $\Delta \max$ & $\Delta \min$ & $\Delta \max / \Delta \min$ & $\Delta \max$ & $\Delta \min$ & $\Delta \max / \Delta \min$ & \multicolumn{1}{l|}{$\begin{array}{l}\text { Torsional } \\
\text { Irregular }\end{array}$} \\
\hline Model 1 (5-storey) & 29.39 & 14.13 & 2.08 & 26.26 & 14.79 & 1.78 & $\begin{array}{l}\text { Torsional } \\
\text { Irregular }\end{array}$ \\
\hline Model 2 (5-storey) & 27.621 & 13.171 & 2.10 & 24.333 & 14.516 & 1.68 & $\begin{array}{l}\text { Torsional } \\
\text { Irregular }\end{array}$ \\
\hline Model 3 (5-storey) & 25.559 & 15.379 & 1.66 & 25.607 & 14.516 & 1.76 & Regular \\
\hline Model 4 (5-storey) & 14.463 & 13.671 & 1.06 & 14.463 & 13.6 & 1.06 & Regular \\
\hline Model 5 (5-storey) & 18.887 & 15.936 & 1.19 & 17.987 & 16.91 & 1.06 & Regular \\
\hline Model 6 (5-storey) & 17.566 & 11.868 & 1.48 & 17.62 & 16.91 & 1.04 & Regular \\
\hline Model 1 (10-storey) & 74.752 & 51.308 & 1.46 & 73.012 & 51.918 & 1.41 & Regular \\
\hline Model 2 (10-storey) & 70.322 & 49.772 & 1.41 & 72.48 & 49.004 & 1.48 & Regular \\
\hline Model 3 (10-storey) & 71.726 & 51.719 & 1.39 & 70.025 & 49.004 & 1.43 & Regular \\
\hline Model 4 (10-storey) & 50.244 & 49.285 & 1.02 & 50.433 & 49.032 & 1.03 & Regular \\
\hline Model 5 (10-storey) & 57.686 & 53.959 & 1.07 & 56.371 & 55.865 & 1.01 & \\
\hline Model 6 (10-storey) & 56.219 & 43.791 & 1.28 & 56.54 & 44.075 & 1.28 & Regular \\
\hline Note: $\Delta$ max = maximum displacement and $\Delta$ min= minimum displacement & \\
\hline
\end{tabular}

\subsection{Storey displacement}

Storey displacement of all the model of five and ten storey building are shown in figure $3(\mathrm{a}), 3(\mathrm{~b}), 3(\mathrm{c})$, and 3(d). In case of five-storey building, model 1 shows the maximum displacement along $\mathrm{x}$-direction followed by model 2, 3, 5, 6, and 4 whereas model 3 shows the maximum displacement along $y$-direction followed by model 2, 1, 5, 6, and 4 . In case of tenstorey building, model 1 shows the maximum displacement along $\mathrm{x}$-direction followed by model 3, 2, 5, 6, and 4. Model 1 also shows maximum displacement along y-direction followed by 2, 3, 5, 6 , and 4 . It has been observed that model 4 shows minimum displacement in all the cases, therefore, the strengthened model 4 indicates high stiffness value, minimum natural time and absence of torsional effect. 


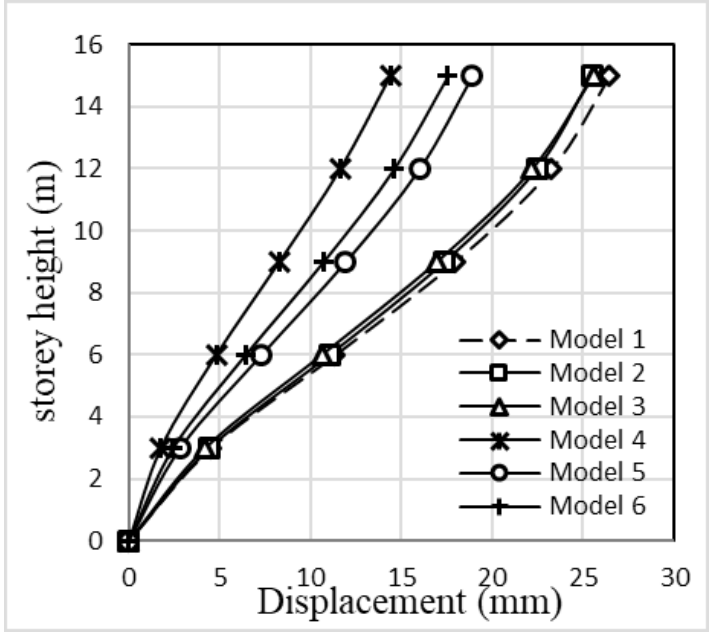

Displacement (x-direction)-five storey

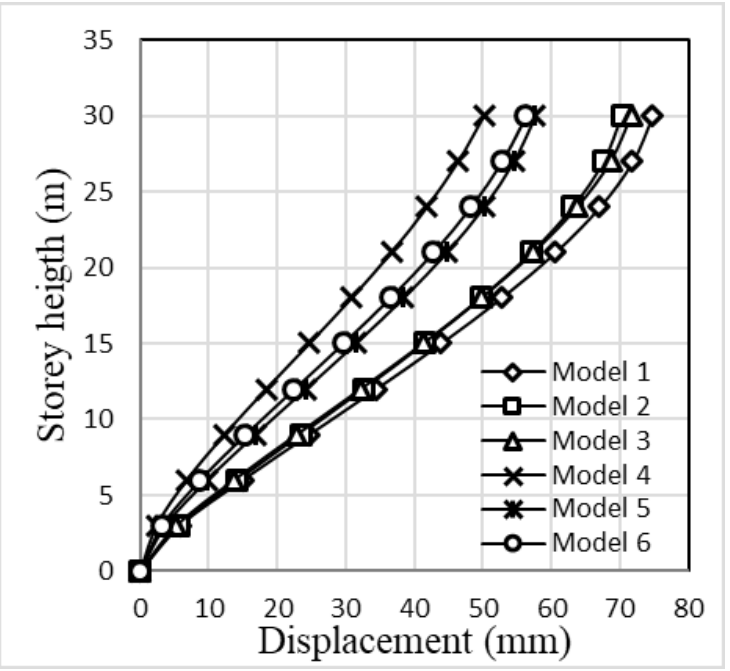

Displacement (x-direction)-ten storey

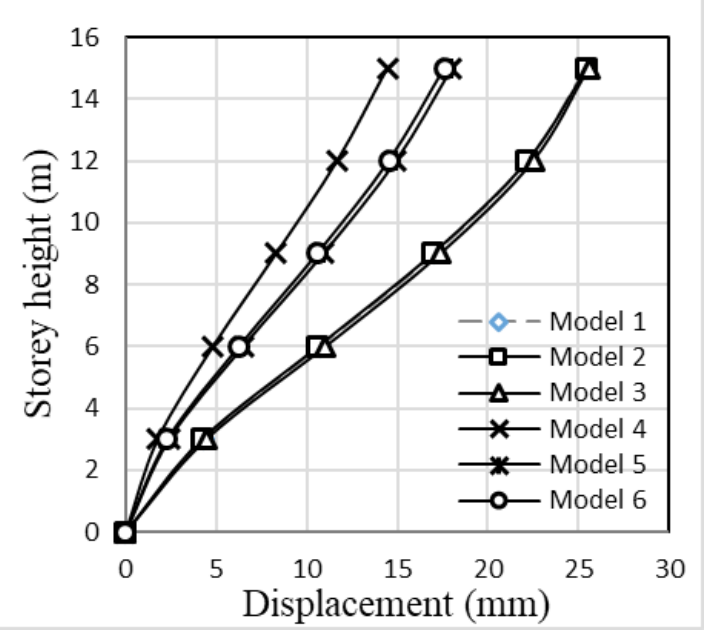

Displacement (y-direction)- five storey

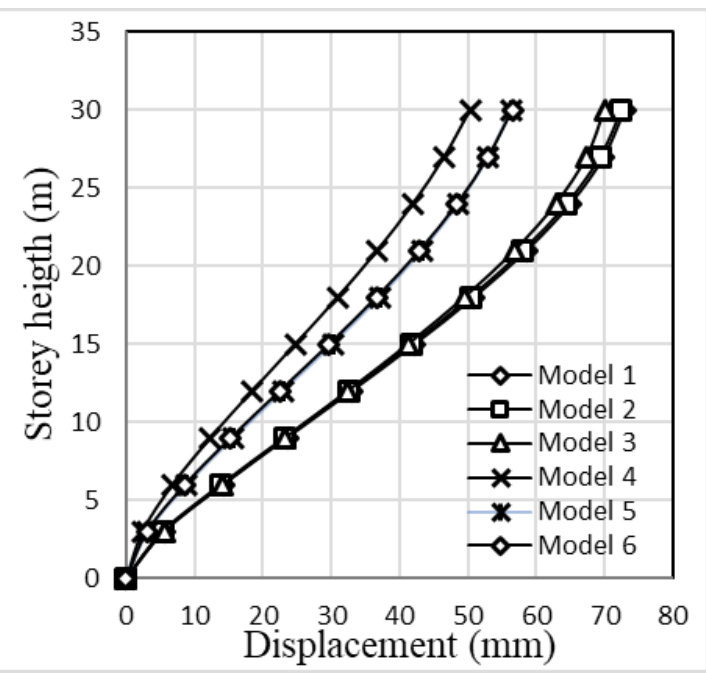

Displacement (x-direction)-ten storey

Figure 3: Storey displacement

\subsection{Drift ratio}

Figure 4(a), 4(b), 4(c) and 4(d) compares the drift ratio of all the five models along both $x$ and $y$ directions. Storey 2 of model 1 (fivestorey building) shows maximum drift ratio of 0.002271 and 0.002152 along $\mathrm{x}$ and $\mathrm{y}$ directions, respectively. Similarly, in ten-storey building, storey 4 of model 1 shows the maximum drift ratio 0.003254 and 0.003163 along $x$ and $\mathrm{y}$ direction, respectively. All the structure demonstrates drift ratio within the prescribed limit as suggested by IS 1893:2002. Hence, it revealed that the structure with maximum drift ratio will have torsional irregularities and viceversa. 


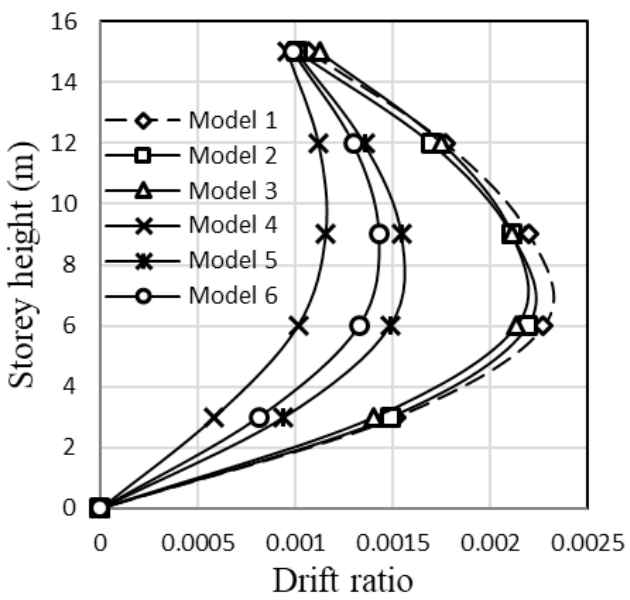

Drift ratio (x-direction)-five storey

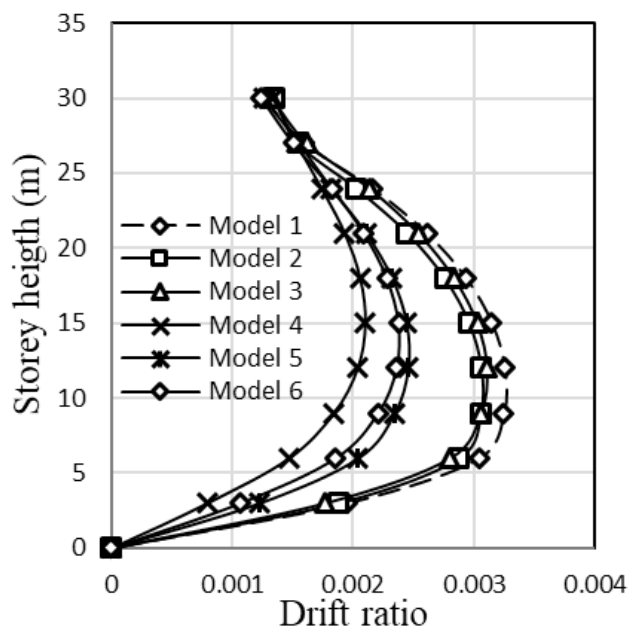

Drift ratio (x-direction)-ten storey

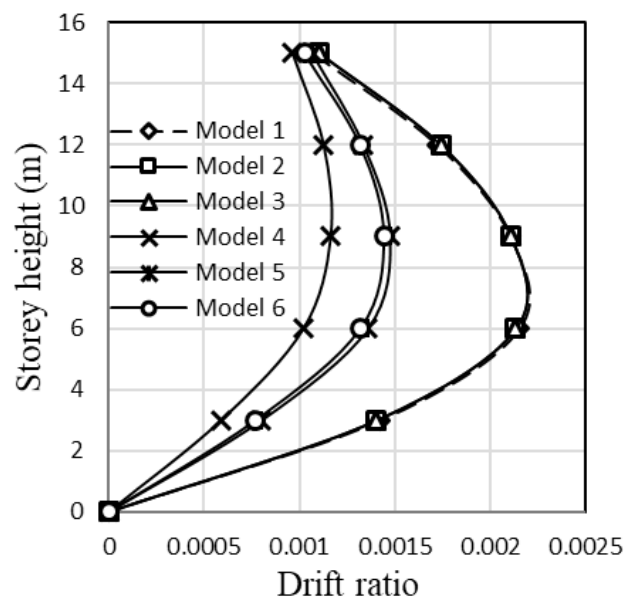

Drift ratio (y-direction)-five storey

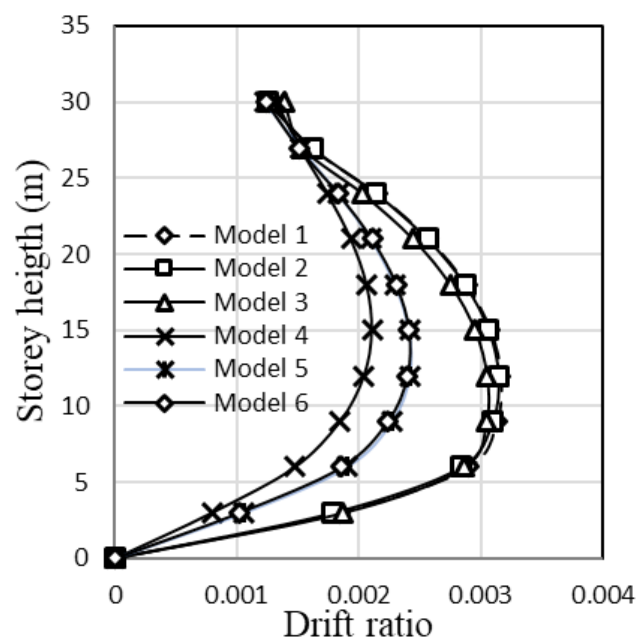

Drift ratio (y-direction)-ten storey

Figure 4: Drift ratio

4.5 Comparsion of structural parameter of L-shape building with different lift core position.

In this study, L- shape building of five storey and ten storey, with different location of lift core wall are compared. Building with lift at outer corner ( model 1), lift at lower edge corner (model 2), and lift upper edge corner (model 3) has maximum drift ratio, displacement and time period but it does not meet the codal provision of torsional irregularity. In case of ten-storey building, all the models have maximum drift ratio, displacement and time period, however, it meet the codal provision of torsional irregularity. In both the five and ten storey building, lift at lower and upper corner (model 4) and lift core at inner corner (model 5) has minimum drift, displacement and time period as well as no torsional effect at all. Finally, it can be concluded that building 
with maximum drift ratio, displacement and time period is more flexible, less stiff and have minimum acceleration, and viceversa.

\section{Conclusions}

From the analyzed model, it can be concluded that building with greater flexibility and longer period design are expected to have less accelerations compared to stiffer building. Higher value of drift limits (> 1.5) shows high tendency of structure torsional irregularity. In this study, model 1, 2, and 3 had high torsional irregularity. The drift ratio and displacement values indicate the dependence of the stiffness and mass concentration on the structure. It has been shown that the model with high strength yielded shorter period which allowed smaller drift limits whereas longer period structures allowed longer drift limits. Moreover, the location of the lift core affects the torsion of an L-shape plan asymmetric building. Designing two lift core at the lower and upper corner (model 4) and lift core at inner corner (model 5) is found to be effective in reducing the torsion.

\section{Reference}

Abdel Raheem, S. E., Ahmed, M. M. M., Ahmed, M. M., \& Abdel-shafy, A. G. A. (2018). Evaluation of plan configuration irregularity effects on seismic response demands of L-shaped MRF buildings. Bulletin of Earthquake Engineering, 16(9), 3845-3869. https://doi.org/10.1007/ s10518-018-0319-7

Abdullah, J., Zaini, S. S., Azizan, N. Z. N., \& Shear, B. (2017). Sensitivity of Lift Core Positions for T-Shaped Reinforced Concrete Buildings Subjected to Seismic Loads. 1st National Colloquium on Wind and Earthquake Engineering (NCWE2017),
(October), 2-5.

Haque, M. (2016). Seismic Performance Analysis of RCC Multi-Storied Buildings with Plan Irregularity. American Journal of Civil Engineering, 4(3), 68. https://doi. org/10.11648/j.ajce.20160403.11

Hoult, R. D., Lumantarna, E., \& Goldsworthy, H. M. (2015). Torsional Displacement for Asymmetric Low-Rise Buildings with RC C-shaped Cores, (8).

IS 1893, I. standard. (2002). Criteria for Earthquake Resistant Design of Structures , Part 1 - General Provisions and Buildings. Bureau of Indian Standards, New Delhi, 1893 Part.

IS 1893, I. standard. (2016). Criteria for Earthquake Resistant Design of Structures , Part 1 - General Provisions and Buildings. Bureau of Indian Standards (Vol. 1893).

IS 456. (2000). Concrete, Plain and Reinforced. Bureau of Indian Standards,New Dehli, $1-114$.

IS 875 : 1987. (1987a). Code of Practice for Design Loads (Other than Earthquake) for Buildings and Structures, Part 1: Dead Loads, 875(Part I).

IS 875 : 1987. (1987b). Code of Practice for Design Loads (Other than Earthquake) for Buildings and Structures, Part 2: Imposed Loads. Bureau of Indian Standards, New Delhi, 18.

Khanal, B., \& Chaulagain, H. (2020). Seismic elastic performance of L-shaped building frames through plan irregularities. Structures, 27(January), 22-36. https:// doi.org/10.1016/j.istruc.2020.05.017

Powale, S. A., \& Pathak, N. J. (2019). A comparative study of torsional effect of earthquake on ' 1 ' and 's' shaped high rise buildings. International Journal of Scientific 
Nepal Engineers' Association, Gandaki and Technology Research, 8(8), 1355-1359.

Rajalakshmi K R, Harinarayanan S, Jiji Anna Varughese, \& Girija K. (2015). Study of Torsion Effects on Building Structures Having Mass and Stiffness Irregularities. International Journal of Engineering Research And, V4(06), 1318-1325. https://doi. org/10.17577/ijertv4is061059

Sarkar, P., Prasad, A. M., \& Menon, D. (2010). Vertical geometric irregularity in stepped building frames. Engineering Structures, 32(8), 2175-2182. https://doi. org/10.1016/j.engstruct.2010.03.020
Setia, S., \& Sharma, V. (2012). Seismic response of R. C. C Building with soft storey. International Journal of Applied Engineering Research, 7(11 SUPPL.), 1335-1339.

Shashwati Sanjay Vahadane, \& Ashok W. Yerekar Sir. (2016). Study of Earthquake Forces by Changing the Location of Lift Core. International Journal of Engineering Research And, V5(06), 194-200. https:// doi.org/10.17577/ijertv5is060300 